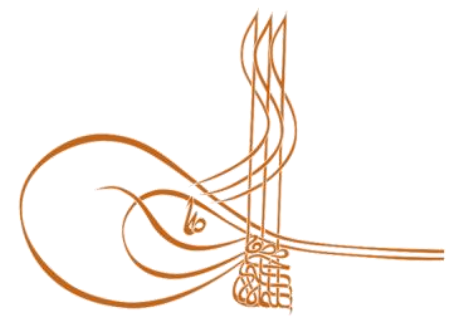

www.turkishstudies.net/economy
Turkish Studies - Economics, Finance, Politics

eISSN: 2667-5625

Research Article / Araştırma Makalesi

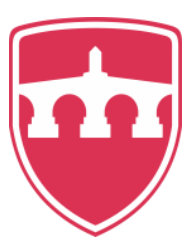

INTERNATIONAL BALKAN

UNIVERSITY

Sponsored by IBU

\title{
Siyasal Pazarlama Reklamlarına Karşı Tutumun Seçmen Memnuniyeti ve Kararına Etkisi: 31 Mart 2019 İstanbul Yerel Seçimleri Üzerine Bir Araştırma*
}

The Effect of Political Marketing Ads on Voter Satisfaction and Decisions: A Research on the Istanbul Local Elections on March 31, 2019

\section{Osman Özdemir**}

\begin{abstract}
Politics is one of the main phenomena that society concentrates on and it is focused on social sciences. The local elections have also frequently been on the agenda with both before and after events. In this context, the effect of political marketing advertisements in these elections, which have a great sociological influence, is examined in this study. The use of marketing practices in politics is a constant situation. While marketing focuses on consumers, political parties focus on voter decisions through candidates, promises and propagandas. It is understood from the information obtained from secondary sources that attitudes towards advertisements and elections affect voter satisfaction and decision; that attitudes towards advertisements affect attitudes towards elections; that voter satisfaction also affects voter decision. The model of the study is on the effect of political advertisements on voter decisions. Voter attitudes and satisfaction are also used as mediating variables in the model. 201 voters residing in Istanbul participad in the survey. The participants were reached in February and March 2019 in Bahçelievler and Bakırköy districts. Survey data were analyzed with SPSS 23.0. As a result, it was concluded that there are significant relationships between the variables and affect each other positively. In addition, the importance of voter decision emerged in the study (Mean: 4.275 - Std. Deviation: 0,208). In the literature, it is emphasized that voters need information about parties and candidates before the election; that they want to vote without any internal conflict at the time of the elections; that they want not to feel guilt after the election. The same results were achieved in this research.
\end{abstract}

Structured Abstract: This study necessary to explain the effect of political marketing advertisements on voter decisions. In this context, the importance put forward marketing practices should be used in politics.

Modern and postmodern political advertisements are used in political campaigns. These may differ in terms of targeted voters, time and cost. (Strömback, 2007). In these campaigns, political advertisements need

\footnotetext{
* 28 Ekim - 01 Kasım 2019 tarihlerinde Antalya'da düzenlenen 11. Uluslararası Güncel Araştırmalarla Sosyal Bilimler Kongresinde sunulan özet bildiriden türetilmiştir.

** Dr. Öğr. Üyesi, Şırnak Üniversitesi, İktisadi ve İdari Bilimler Fakültesi, İşletme Bölümü

Asst. Prof. Dr., Sirnak University, Faculty of Economics and Administrative Sciences, Department of Business ORCID 0000-0001-8880-1459

osmanozdemir03@hotmail.com

Cite as/ Atıf: Özdemir, O. (2020). Siyasal pazarlama reklamlarına karşı tutumun seçmen memnuniyeti ve kararına etkisi: 31 Mart 2019 İstanbul yerel seçimleri üzerine bir araştırma, Turkish Studies - Economy, 15(1), 429-439. https://dx.doi.org/10.29228/TurkishStudies.39382

Received/Geliş: 19 October/Ekim 2019

Accepted/Kabul: 25 March/Mart 2020

Checked by plagiarism software

Copyright $(C$ INTAC LTD, Turkey 
to be informative, interesting, credible, prejudiced and fair (Pinkleton vd. 2002). Political parties and candidates allocate and place advertisements in election campaigns in order to influence voter decisions (Ediraras vd. 2013). On the other hands, developments in information technologies also affect politics. Especially the internet and social media affect political parties and candidates positively and negatively (Üniver, 2013). In this study, the importance of all these issues is examined. In this context, the effect of political marketing advertisements on voter's satisfaction and decision in elections, which have a great sociological influence, is examined in this study.

Questionnaire form was prepared while creating data set. Research was conducted on voter residing in Bahçelievler and Bakırköy districts of İstanbul. Both districts have different characteristics, so were preferred. In this study, the scales of attitude towards advertisements and elections variables were obtained from Pinkleton et al. (2002); the scale of satisfaction variable was obtained from O'Cass (2002); the scale of decison variable obtained from Burroughs et al. (2002). A scale (5-point likert) standart questionnaire was collected during face to face interviews with the participants. Simple random sampling method was used to determine the participants. 201 questionnaires were found suitable to evaluate. The participants were reached in February and March 2019. Survey data were analyzed with SPSS 23.0.

According to the correlation analysis results, there are a positive, moderate or weak linear relationships between all variables. The Pearson correlation values indicate that these relationships are within the $99 \%$ confidence interval. On the other hands, the regression analysis results were evaluated in general, it was concluded that independent variables had a positive effect on the dependent variables and all hypotheses established were accepted. Analysis results are similar to the analysis results in the literature. The regression analysis results can also listed as follows.

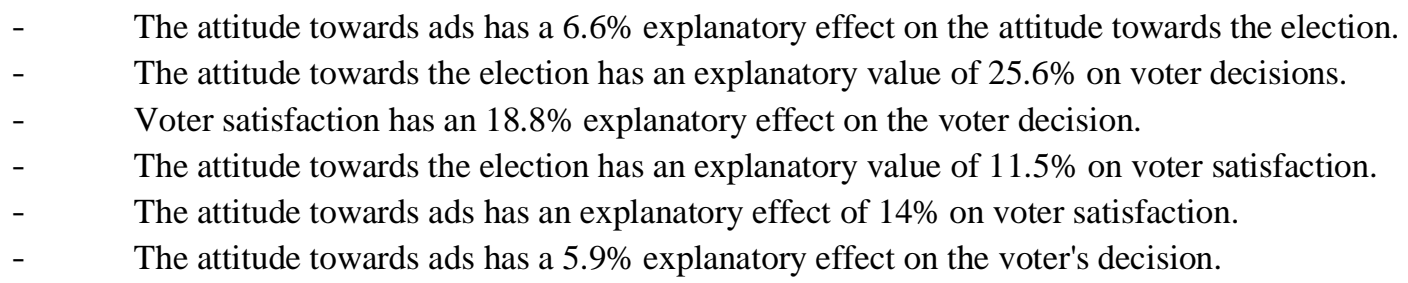

In this study, six hypotheses were established and all of them were accepted. Thus, it is said the importance of the advertisements used in the elections have increased. Today advertisements made via internet and social media frequently. The cost-effectiveness, the ability to reach different voters, and the speed of use of online advertising in the elections have increased. The content and liking of advertisements also affect voter decisions. On the other hands, the importance of the elections for the participants was revealed as a result of the analysis (Mean: 4.257). The positive attitude towards the elections is also related to the fact that the election is the social issue. It also makes an election every 4-5 years (general elections every 4 years; local elections every 5 years). In this context, it also affects the satisfaction and decision of voters. The campaigns of the parties and candidates; the survey results announced by the research companies increase the satisfaction. The importance of voter decision has emerged in the study (Mean: 4.275). Voters with the party and candidates to vote for or not; voters who will vote or not or undecided to determine the election results. In this context, it is necessary to use political marketing advertisements in election campaigns in order to call for voting and to support parties and candidates. For future studies on Istanbul, different districts can be included in the study and can be repeated by reaching more participants. The study can also be measured on diffirent cities.

Keywords: Politics, Voter Decision, Regression Model.

Öz: Siyaset, toplumun üzerine yoğunlaştığı temel olgulardan biridir ve sosyal bilimler alanında üzerine yoğun olarak durulmaktadır. 2019 Yerel Seçimleri de hem öncesindeki hem de sonrasındaki olaylar ile gündemi sıkça meşgul etmiştir. Bu bağlamda, sosyolojik etkisi büyük olan bu seçimlerde siyasal pazarlama reklamlarının etkisinin ne olduğu bu çalışmada incelenmektedir. Pazarlama uygulamalarının siyasette kullanımı devamlı karşılaşılan bir durumdur. Pazarlama tüketiciye odaklanırken siyasi partiler adayları, vaatleri ve propagandaları ile seçmen kararlarına odaklanmaktadır. Reklamlara karşı tutum ve seçimlere karşı tutumun seçmen memnuniyetini ve kararını etkilediği; reklamlara karşı tutumun seçimlere karşı tutumu 
etkilediği; seçmen memnuniyetinin de seçmen kararını etkilediği ikincil kaynaklardan edilen bilgilerden anlaşılmaktadır. Bu bağlamda çalışmanın modeli siyasal reklamların seçmen kararlarına olan etkisi üzerinedir. Seçmenlerin tutumları ile memnuniyet durumları da modelde aracı değişken olarak kullanılmaktadır. İstanbul'da ikamet eden 201 seçmen ankete katılmıştır. Katılımcılara 2019 yılı Şubat ve Mart aylarında Bahçelievler ve Bakırköy ilçelerinde ulaşılmıştır. Anket verileri SPSS 23.0 ile analiz edilmiştir. Analiz sonucunda değişkenler arasında anlamlı ilişkilerin olduğu ve birbirlerini pozitif yönde etkilediği sonucuna ulaşılmıştır. Ayrıca seçmen kararının önemi de çalışmada ortaya çıkmıştır (Mean: 4.275 Std. Deviation: 0,208). Literatürde seçmenlerin seçim öncesinde parti ve adaylar hakkında bilgiye ihtiyaç duymaları; seçim anında iç çatışma yaşamadan oy kullanmayı istemeleri; seçim sonrasında ise suçluluk duygusu hissetmemeyi istemeleri üzerinde durulmaktadır. Aynı sonuçlara bu araştırmada da ulaşılmıştır.

Anahtar Kelimeler: Siyaset, Seçmen Kararı, Regresyon Modeli

\section{Giriş}

Siyaset, sosyal bilimlerin en eski bilim dallarından birisi olarak nitelendirilmektedir. Genel anlamıyla bireylerin ve toplumların yönetilmesi olarak kabul edilmektedir ve literatürde sıkça yer bulmaktadır (Kapani, 2012: 17-25). Pazarlama ise iktisattan türeyen bir bilim dalı olmakla birlikte günümüzde önemle üzerinde durulmaktadır. $\mathrm{Bu}$ bağlamda siyasal pazarlama, pazarlama uygulamalarının siyasette uygulanması olarak ifade edilmektedir. Siyasal pazarlamada parti ve adayların seçmenlere sunulması; mitinglerde ya da yayın organları aracılığıyla propagandalar yapılarak seçmenlerin bilgilendirilmesi ve ikna edilmesi; böylece oylarını almaya çalışılması söz konusudur.

Seçimlerde kullanılan reklamların önemi ve etkisi günümüzde artmıştır. Basılı ve görsel yayınlar üzerinden yapılan reklamlar yerini internet ve sosyal medya üzerinden yapılan reklamlara bırakmaktadır. Maliyetinin uygunluğu, farklı kitlelere ulaşma gücüne sahip olması ve hızlılığı seçimlerde online reklamların kullanılmasını artırmıştır. Reklamların içeriği ve beğenilmesi de seçmen kararlarını etkilemektedir. Seçim dönemlerinde seçim afişleri, posterler, işitsel, yazılı ve görsel reklamlar, radyo ve televizyon demeçleri, epostalar, internet reklamları kitlelere ulaşmak amacıyla tercih edilen siyasal pazarlama reklamlarına örnek oluşturmaktadır. Modern ve postmodern siyasal reklamlara örnek olan bu uygulamalar hedeflenen kitle, zaman ve maliyet açısından farklılaşabilmektedir (Strömback, 2007).

Siyasal pazarlama reklamları seçmenlerin memnuniyet ve kararlarında önem arz etmektedir. Bu bağlamda reklamların inandırıcı, bilgi verici, ilgi çekici, önyargısız ve adil olması gerekmektedir (Pinkleton vd. 2002). Çalışmanın kavramsal çerçeve ve bulgular bölümünde de bu kavramlar detaylı biçimde açıklanacaktır.

\section{Kavramsal Çerçeve}

\subsection{Siyasal Pazarlama}

Eski çağlardan günümüze siyaset, pazarlama dahil diğer disiplinlerden beslenmektedir, fakat İkinci Dünya Savaşı sonrasında dünya çapında salt bir araştırma konusu olmuştur. Lanner'e göre kentleşme, okuryazarlık ve kitle iletişim araçları bireylerin ekonomik, kültürel ve siyasal olarak topluma ve seçimlere katılımını etkilemiş̧tir (Kahraman, 2011: 57).

Siyasetin halka dayandırılması amacıyla seçimlerin yapılması (Kapani, 2012: 143) ve bu seçimlerde de pazarlamadan yararlanılması söz konusudur. Bu nedenle, siyasi partiler halkın kararlarını etkilemek için siyasal pazarlama faaliyetlerinden yararlanmaktadır. Bilişim teknolojilerindeki gelişmeler de siyaseti etkilemektedir. Özellikle internet ve sosyal medya hem siyasi partileri hem de adayları olumlu ve olumsuz olarak etkilemektedir (Ünüvar, 2013: 15). Bu olumlu ve olumsuz etkileri yönetmek amacıyla parti ve adaylar medyaya, topluma ve parti tabanına yoğunlaşmaktadır (Ediraras vd, 2013: 584). 
Seçmenlerin psikolojik, sosyolojik, ekonomik, kültürel ve siyasal etkenlere dayanan kararları bulunmaktadır. Yapılan araştırmalar bu etkenlerin birbirinden soyutlanamayacağını ve bir bütün olarak düşünülmesi gerektiğini belirtmektedir (Kahraman, 2011: 67). Siyasal pazarlama reklamlarında da bu etkenler üzerinde durularak seçmen kararlarını etkilemek amaçlanmaktadır.

\subsection{Siyasal pazarlama reklamları}

Reklamlar tüketicileri bir ürün hakkında bilgilendirme, ikna etme ve hatırlatma işlevini görmekteyken siyasal pazarlama reklamları da propaganda aracı olarak kullanılmaktadır (Powell ve Cowart 2015). Siyasi parti ve adaylar seçmen kararlarına etki etmek amaciyla seçim kampanyalarında reklamlara bütçe ayırmakta ve yer vermektedirler (Ediraras vd. 2013: 385). Siyasal pazarlama reklamları geçmişte parti ve medya odaklıyken günümüzde pazarlama odaklı gerçekleşmektedir (Strömback, 2007). Bu bağlamda seçim çalışmaları geçmişte miting alanlarında yapılırken günümüzde televizyon yayınları ve online mecrada gerçekleştirilmektedir (Yang vd. 2016). Seçmenlere ulaşmak için Facebook, Twitter, Instagram ve Youtube gibi sosyal medya mecraları da kullanılmaktadır. Amerika'da başkanlık seçimlerinde Obama (2008) ve Trump'ın (2016) sosyal medyadan yararlanıp kitlelere ulaşması ve siyasal pazarlama reklamlarına yer vermesi buna örnek oluşturmaktadır (Pal ve Gonawela, 2017).

Seçmen tutumları parti, parti başkanı ve adaylarından etkilenmektedir. Obama, Erdoğan, Trump ve Modi'nin siyasal başarılarında siyasal pazarlama reklamları etkili olmaktadır. Siyasal iletişim analizi yapılan araştırmalarda önemli aktörler, konular ve mesajlar ile seçmen tutumlarının değişebileceğini belirtmiştir (Pal ve Gonawela, 2017). Çünkü seçmenlerin kararlarına bilişsel ve davranışsal tutumlarından ziyade duygusal tutumlarının etkisi bulunmaktadır. Duygusal tutumları etkileyebilecek mesaj içeriklerinin hazırlanması da önem taşımaktadır (Mejova ve Srinivasan, 2012). Diğer taraftan teknolojinin gelişmesi; sosyal medyadaki siyasal içeriklerin ve yorumların analizinin yapılabilir hale gelmesi siyasal reklamların ve mesaj içeriklerinin etkisini ölçmeyi kolaylaştırmaktadır (Bastos ve Mercea, 2016). Örneğin, Trump 2019 Eylül ayında Twitter'da 757 paylaşım yapmıştır (trthaber.com). Bu paylaşımlar ve paylaşımlara yönelik yorumlar üzerine nitel araştırmalar yapmak da mümkündür. Böylece sosyal medyanın kitlelere ulaşmadaki rolü ortaya çıkmaktadır.

Seçmenlerin memnun edilmesi sadece ulusal değil küresel bağlamda da önem arz etmektedir. Seçmenlerin güdülenmesi ve memnun edilmesi için siyasal reklamlarda ulusal ve küresel bazda yatırımlardan, sağlık, eğitim, hukuk, güvenlik ve uluslararası ilişkiler unsurlarından bahsedilmesi gerekmektedir (McNeill ve Ottersen, 2015). Ayrıca seçmenlerin geçmiş seçimlerdeki deneyimlerinin; parti ve adayların seçmen beklentilerini karşılama durumlarının da seçmen memnuniyetinde etkisi bulunmaktadır (O'Cass, 2002). Bu bağlamda gerçekleştirilen faaliyetlerden bahsedilmesi de gerekmektedir. Diğer taraftan kadınların ve erkeklerin; gençlerin ve yaşlıların vb. gibi toplumun farklı özellikteki kesimlerinin seçimlere yaklaşımları farklılık gösterebilmektedir. Sunulan projeler -vaatler- ile bu seçmenlerin memnuniyeti sağlanabilmektedir (Ross vd. 2015: 251253).

\subsection{Karar verme}

Siyasal pazarlama reklamları son y1llarda profesyonel biçimde yapılmaktadır. Özellikle partilerin ve adayların zayıf olduğu, seçimlere katılımın yüksek olduğu zamanlarda siyasal pazarlama reklamları seçmen kararlarını etkilemektedir (Strömback, 2007: 49-52). Siyasette seçmenlerin heterojen olması demokrasiye katkı sağlarken siyasal çekişmeyi de artırmaktadır. $\mathrm{Bu}$ bağlamda, parti ve adaylara yönelik olumlu, olumsuz ya da nötr düşüncesi olan seçmenlerle etkileşime yoğunlaşan parti ve adayların seçmen kararlarını belirleyebileceği ileri sürülmektedir (Ross vd. 2015: 251-253).

Reklamlara karşı tutum ve seçimlere karşı tutumun seçmen memnuniyetini ve kararını etkilediği; reklamlara karşı tutumun seçimlere karşı tutumu etkilediği; seçmen memnuniyetinin de 
seçmen kararını etkilediği ikincil kaynaklardan edilen bilgilerden anlaşılmaktadır. Bu çalışmada söz konusu bu etki Şekil 2'deki model üzerinden araştırılmıştır.

Partiler ya da adaylar arasında seçim yapıp karar verme süreci seçmenler için zor olabilmektedir. Karar verme sürecinde seçmenler daha fazla bilgiye ihtiyaç duymakta ve bu bilgiler üzerinden değerlendirmelerde bulunmaktadır. Ayrıca bu süreçte içsel çatışma ve suçluluk duygusu yaşamamak için doğru kararı vermeye çalışmaktadır (Burroughs vd. 2002).

\section{Yöntem}

\subsection{Araştırmanın Yöntemi ve Örneklemi}

Çalışmanın veri seti oluşturulurken anket formu hazırlanmıştır. İstanbul ili Bahçelievler ve Bakırköy ilçelerinde ikamet eden seçmenler üzerine araştırma gerçekleştirilmiştir. Araştırmanın bu bölgede yapılmasın nedeni İstanbul ilinin tüm partiler açısından önemli olması ve kapsamlı seçim faaliyetleri yürütmelerinden dolayıdır. 5'li Likert ölçeğinde hazırlanmış standart bir anket formu aracılığıyla katılımcılarla yüzyüze görüşmeler yapılarak ihtiyaç duyulan veriler toplanmıştır. Katılımcıların belirlenmesinde kolayda örnekleme yöntemi kullanılmıştır. Toplanan anketlerden 201 tanesi değerlendirmeye uygun bulunmuştur. Katılımcılara 2019 yılı Şubat ve Mart aylarında Bahçelievler ve Bakırköy ilçelerinde ulaşılmıştır. Anket verileri SPSS 23.0 ile analiz edilmiştir.

Çalışmada reklamlara ve seçimlere karşı tutum değişkenlerinin ölçekleri Pinkleton vd. (2002)'nin çalışmasından; memnuniyet değişkeninin ölçeği O'Cass (2002)'ın çalışmasından; karar değişkeninin ölçeği Burroughs vd. (2002)'nin çalışmasından elde edilmiştir.

\subsection{Araştırmanın Amacı ve Hipotezleri}

Çalışmada reklamlara ve seçimlere karşı tutumun seçmen memnuniyeti ve kararı üzerine etkisini araştırmak amaçlanmaktadır. Ayrıca seçmenlerin memnuniyetinin kararlarında etkisi de araştırılmaktadır. Bu amaçlarla aşağıdaki hipotezler geliştirilmiştir.

H1: Reklamlara karşı tutumun seçimlere karşı tutum üzerinde olumlu bir etkisi vardır.

H2: Reklamlara karş1 tutumun seçmen memnuniyeti üzerinde olumlu bir etkisi vardır.

H3: Seçimlere karşı tutumun seçmen memnuniyeti üzerinde olumlu bir etkisi vardır.

H4: Reklamlara karşı tutumun seçmen kararı üzerinde olumlu bir etkisi vardır.

H5: Seçimlere karşı tutumun seçmen kararı üzerinde olumlu bir etkisi vardır.

H6: Seçmen memnuniyetinin seçmen kararı üzerinde olumlu bir etkisi vardır.

\section{Araştırmanın Bulguları}

Çalışmada faktör, güvenirlik, korelasyon ve regresyon analizleri yapılmıştır. Faktör analizi sonucunda bir ifade; güvenilirlik analizi sonucunda da bir ifade analizden çıkarılmış olup yeniden faktör ve güvenilirlik analizi yapılarak Tablo 1'deki sonuçlara ulaşılmıştır. 
Tablo 1: Ölçeklere İlișkin Analiz Sonuçları

\begin{tabular}{|c|c|c|c|c|}
\hline & $\begin{array}{l}\text { Soru } \\
\text { Iffadesi }\end{array}$ & 旋 & : & 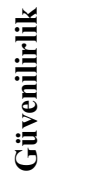 \\
\hline \multirow[t]{9}{*}{ Karar } & Kararımın doğruluğu veya yanlışlığı konusunda ikilem yaşamam & 890 & \multirow[t]{9}{*}{42,495} & \multirow[t]{9}{*}{,943 } \\
\hline & Değerlerim açısından kararımda hiçbir iç çatışma olmazdı & ,822 & & \\
\hline & Kararım için suçluluk duymuyorum & 814 & & \\
\hline & Vereceğim kararla ilgili his ve düşüncelerimde bir çatışma olmaz & ,813 & & \\
\hline & Bu benim için zor bir karar olmayacaktır & 811 & & \\
\hline & Aday ve partiler hakkında daha fazla bilgiye ihtiyacım yok & ,770 & & \\
\hline & Hangi adaya oy vereceğimi biliyorum & ,766 & & \\
\hline & Kararımla ilgili herhangi bir iç çatışma hissetmeyeceğim & ,732 & & \\
\hline & Bu seçimde vereceğim oy, benim için açık bir karar olacaktır & ,633 & & \\
\hline \multirow{5}{*}{$\begin{array}{c}\text { Reklama } \\
\text { Karşı } \\
\text { Tutum }\end{array}$} & Siyasal reklamlar inandırıcıdır & ,861 & \multirow[t]{5}{*}{9,166} & \multirow[t]{5}{*}{0,904} \\
\hline & Siyasal reklamlar bilgi vericidir & ,855 & & \\
\hline & Siyasal reklamlar adildir & ,848 & & \\
\hline & Siyasal reklamlar ön yargısızdır & ,838 & & \\
\hline & Siyasal reklamlar ilgi çekicidir & ,763 & & \\
\hline \multirow{3}{*}{$\begin{array}{c}\text { Seçime } \\
\text { Karş1 } \\
\text { Tutum }\end{array}$} & Her seçim benim içi değerlidir &, 882 & \multirow[t]{3}{*}{16,643} & \multirow[t]{3}{*}{0,899} \\
\hline & Her seçim benim içi önemlidir & 864 & & \\
\hline & Oy vermeyi severim & ,799 & & \\
\hline \multirow[t]{3}{*}{ Memnuniyet } & Önceki seçimde oy verdiğim partiden memnunum & ,887 & \multirow[t]{3}{*}{7,728} & \multirow[t]{3}{*}{0,922} \\
\hline & Önceki seçimde oy verdiğim adaydan memnunum & ,867 & & \\
\hline & Önceki seçimde oy verdiğim partinin politikalarından memnunum &, 856 & & \\
\hline
\end{tabular}

Faktörlerin toplam açıklayıcılığı 76,032 olarak bulunmuştur. KMO ölçek geçerliliği 0,884 olarak bulunmuş olup örnekleme yeterliliğinin yüksek olduğu sonucuna ulaşılmış̧ır. Bartlett küresellik testi sonucunda p değeri 0,000 (Sig. < 0,05); Ki kare değeri 3401,994; standart hata değeri 190 olarak bulunmuştur. Bu bağlamda değişkenler arasında anlamlı bir ilişsinin olduğu sonucu bulunmuştur. Ayrıca güvenilirlik analizi sonucu olarak ise Cronbach's Alpha değeri 0,922 olarak bulunmuştur. Analiz yapmaya uygun bulunan bu sonuçlara dayanarak korelasyon ve regresyon analizine geçilmiştir.

\subsection{Demografik Bilgiler}

Katılımcıların demografik özelliklerini gösteren Tablo 2'de cinsiyet, yaş, eğitim, medeni hal, meslek ve gelir bilgileri yer almaktadır.

Tablo 2. Demografik Bilgiler

\begin{tabular}{|c|c|c|c|c|c|c|}
\hline Cinsiyet & \multicolumn{3}{|c|}{$\begin{array}{l}\text { Kadın } \\
97 \\
(\% 48)\end{array}$} & \multicolumn{3}{|c|}{$\begin{array}{l}\text { Erkek } \\
104 \\
(\% 52)\end{array}$} \\
\hline Yaş & $\begin{array}{c}25 \text { ve alt } \\
76 \\
(\% 37.8)\end{array}$ & $\begin{array}{c}26-35 \\
66 \\
(\% 32.8)\end{array}$ & $\begin{array}{c}36-45 \\
22 \\
(\% 10.9)\end{array}$ & $\begin{array}{c}46-55 \\
21 \\
(\% 10.4)\end{array}$ & $\begin{array}{c}56-65 \\
12 \\
(\% 6)\end{array}$ & $\begin{array}{c}66 \text { ve üstü } \\
4 \\
(\% 2)\end{array}$ \\
\hline Eğitim & $\begin{array}{c}\text { Ortaöğretim } \\
29 \\
(\% 14.4)\end{array}$ & $\begin{array}{c}\text { Lise } \\
63 \\
(\% 31.3)\end{array}$ & $\begin{array}{c}\text { Önlisans } \\
32 \\
(\% 15.9)\end{array}$ & $\begin{array}{c}\text { Lisans } \\
59 \\
(\% 29.4)\end{array}$ & $\begin{array}{c}\text { Y. Lisans } \\
17 \\
(\% 8.5)\end{array}$ & $\begin{array}{c}\text { Doktora } \\
1 \\
(\% 0.5)\end{array}$ \\
\hline $\begin{array}{c}\text { Medeni } \\
\text { Hal }\end{array}$ & \multicolumn{3}{|c|}{$\begin{array}{l}\text { Bekar } \\
123 \\
(\% 61)\end{array}$} & \multicolumn{3}{|c|}{$\begin{array}{c}\text { Evli } \\
78 \\
(\% 39)\end{array}$} \\
\hline Meslek & \multicolumn{2}{|c|}{$\begin{array}{c}\text { Özel Sektör } \\
147 \\
(\% 73) \\
\end{array}$} & \multicolumn{2}{|c|}{$\begin{array}{c}\text { Kamu Sektörü } \\
24 \\
(\% 12) \\
\end{array}$} & \multicolumn{2}{|c|}{$\begin{array}{c}\text { Öğrenci } \\
30 \\
(\% 15) \\
\end{array}$} \\
\hline Gelir & $\begin{array}{c}2000 \mathrm{TL} \text { ve alt } 1 \\
57 \\
(\% 28.4)\end{array}$ & $\begin{array}{c}2001-3000 \mathrm{TL} \\
84 \\
(\% 41.8)\end{array}$ & $\begin{array}{c}3001-4000 \mathrm{TL} \\
26 \\
(\% 12.9)\end{array}$ & $\begin{array}{c}4001-5000 \mathrm{TL} \\
14 \\
(\% 7)\end{array}$ & $\begin{array}{c}5001-7500 \mathrm{TL} \\
11 \\
(\% 5.5)\end{array}$ & $\begin{array}{c}7501 T L \text { ve üstü } \\
9 \\
(\% 4.5)\end{array}$ \\
\hline
\end{tabular}


Demografik özellikler değerlendirildiğinde kadın ve erkeklerin dengeli bir dağılıma sahip olduğu görülmektedir. Katılımcıların \%70.6'sının 35 yaş ve altında olduğu; \%61'inin bekar olduğu; \%73'ünün özel sektörde çalıştığı; \%54.7'sinin 2001-4000TL arasında bir gelire sahip olduğu sonucuna ulaşılmıştır.

\subsection{Korelasyon Analizi}

Korelasyon analizi değişkenlerin bağımlı ya da bağımsız olmasına bakmaksızın aralarındaki ilişkiyi ölçerek bu ilişkinin yönünü ve derecesini vermektedir (Durmuş vd. 2011). Analiz sonucu korelasyon katsayısı -1 ile +1 arasında bir değer almaktadır ve 1'e yaklaştıkça ilişkinin kuvveti artmaktadır. Eksi (-) değer değişkenler arası ters yönde; artı (+) değer doğru yönde doğrusal ilişkiyi vermektedir. Bu bağlamda çalışmadaki ilişkiler Pearson korelasyon katsayısı ile belirlenmiştir (Gegez, 2010) ve korelasyon analizi sonuçları Tablo 3’te gösterilmiştir.

Tablo 3: Korelasyon Sonuçları

\begin{tabular}{|c|c|c|c|c|c|}
\hline & & Karar & $\begin{array}{c}\text { Reklama } \\
\text { Karş1 Tutum }\end{array}$ & $\begin{array}{c}\text { Seçime } \\
\text { Karş1 Tutum }\end{array}$ & Memnuniyet \\
\hline Karar & $\begin{array}{l}\text { Pearson Correlation } \\
\text { Sig. (2-tailed) }\end{array}$ & 1 & & & \\
\hline $\begin{array}{c}\text { Reklama } \\
\text { Karşı Tutum }\end{array}$ & $\begin{array}{l}\text { Pearson Correlation } \\
\text { Sig. (2-tailed) }\end{array}$ & $\begin{array}{r}, 243^{* *} \\
, 001\end{array}$ & 1 & & \\
\hline $\begin{array}{c}\text { Seçime } \\
\text { Karşı Tutum } \\
\end{array}$ & $\begin{array}{l}\text { Pearson Correlation } \\
\text { Sig. (2-tailed) }\end{array}$ & $\begin{array}{r}, 506^{* *} \\
, 000\end{array}$ & $\begin{array}{r}, 256^{* *} \\
, 000\end{array}$ & 1 & \\
\hline Memnuniyet & $\begin{array}{l}\text { Pearson Correlation } \\
\text { Sig. (2-tailed) }\end{array}$ & $\begin{array}{r}, 434^{* *} \\
, 000\end{array}$ & $\begin{array}{r}, 374^{* *} \\
, 000\end{array}$ & $\begin{array}{r}, 339^{* * *} \\
, 000\end{array}$ & 1 \\
\hline
\end{tabular}

**. Correlation is significant at the 0.01 level (2-tailed).

Korelasyon analizi sonuçlarına göre tüm değişkenler arasında pozitif yönde orta veya zayıf doğrusal bir ilişki bulunmaktadır. Bu ilişkilerin \%99 güven aralığında olduğu ise Tablo 3 'teki Pearson korelasyon değerleri ile anlaşılmaktadır.

\subsection{Regresyon Analizi}

Regresyon analizi bağımlı değişkenin bağımsız değişken(ler) tarafindan nasıl açıklandığını ve aralarındaki nedensellik ilişkisini tahmin etmektedir (Nakip, 2005). Bu tahminlerde ilişkilerin yönü, derecesi ve bilinmeyen diğer değerler ortaya çıkmaktadır (Durmuş vd. 2011).

Tablo 4: Regresyon Analizi Sonuçları

\begin{tabular}{|c|c|c|c|c|c|c|c|}
\hline \multirow[b]{2}{*}{ Model } & \multicolumn{2}{|c|}{$\begin{array}{c}\text { Unstandardized } \\
\text { Coefficients }\end{array}$} & $\begin{array}{c}\text { Standardized } \\
\text { Coefficients }\end{array}$ & \multirow[t]{2}{*}{$\mathrm{t}$} & \multirow{2}{*}{$\mathrm{p}$} & \multirow[b]{2}{*}{$\mathrm{R}$} & \multirow[b]{2}{*}{ R Square } \\
\hline & B & St. Hata & Beta & & & & \\
\hline $\begin{array}{c}\text { (Constant) } \\
\text { Reklama } \\
\text { Kars1 Tutum }\end{array}$ & $\begin{array}{r}3,625 \\
, 242\end{array}$ & $\begin{array}{l}, 178 \\
, 065\end{array}$ &, 256 & $\begin{array}{r}20,385 \\
3,737\end{array}$ & $\begin{array}{l}, 000 \\
, 000\end{array}$ &, $256^{\mathrm{a}}$ & ,066 \\
\hline
\end{tabular}

a. Dependent Variable: Seçime Karşı Tutum

Regresyon eşitliği "Seçime Karşı Tutum = 3,625 + 0,256 * Reklama Karşı Tutum" şeklinde oluşturulmuştur. Anlamlllı (p) değeri 0,05 'ten küçüktür, bu bağlamda eşitliğin istatistiksel olarak anlamlı olduğu sonucuna ulaşılmaktadır. Reklama karşı tutumun seçime karşı tutum üzerinde $\% 6,6$ oranında açıklayıcılığı bulunmaktadır ve bu sonuçlar H1 hipotezini desteklemektedir. 
Tablo 5: Regresyon Analizi Sonuçları

\begin{tabular}{|c|c|c|c|c|c|c|c|}
\hline \multirow[b]{2}{*}{ Model } & \multicolumn{2}{|c|}{$\begin{array}{c}\text { Unstandardized } \\
\text { Coefficients } \\
\end{array}$} & \multirow{2}{*}{$\begin{array}{c}\begin{array}{c}\text { Standardized } \\
\text { Coefficients }\end{array} \\
\text { Beta }\end{array}$} & \multirow[t]{2}{*}{$\mathrm{t}$} & \multirow{2}{*}{$\mathrm{p}$} & \multirow[b]{2}{*}{$\mathrm{R}$} & \multirow[b]{2}{*}{ R Square } \\
\hline & $\mathrm{B}$ & St. Hata & & & & & \\
\hline $\begin{array}{l}\text { (Constant) } \\
\text { Seçime } \\
\text { Kars1 Tutum }\end{array}$ & $\begin{array}{l}2,391 \\
, 444\end{array}$ & $\begin{array}{l}, 234 \\
, 054\end{array}$ &, 506 & $\begin{array}{c}10,238 \\
8,277\end{array}$ & $\begin{array}{l}, 000 \\
, 000\end{array}$ &, $506^{\mathrm{a}}$ & ,256 \\
\hline
\end{tabular}

a. Dependent Variable: Karar

Regresyon eşitliği "Karar $=\mathbf{2 , 3 9 1}+\mathbf{0 , 5 0 6}$ * Seçime Karşı Tutum" şeklinde oluşturulmuştur. Anlamlılık (p) değeri 0,05 'ten küçüktür, bu bağlamda eşitliğin istatistiksel olarak anlamlı olduğu sonucuna ulaşılmaktadır. Seçime karşı tutumun seçmen kararları üzerinde \%25,6 oranında açıklayıcılığı bulunmaktadır ve bu sonuçlar H5 hipotezini desteklemektedir.

Tablo 6: Regresyon Analizi Sonuçları

\begin{tabular}{|c|c|c|c|c|c|c|c|}
\hline \multirow[b]{2}{*}{ Model } & \multicolumn{2}{|c|}{$\begin{array}{c}\text { Unstandardized } \\
\text { Coefficients }\end{array}$} & \multirow{2}{*}{$\begin{array}{c}\begin{array}{c}\text { Standardized } \\
\text { Coefficients }\end{array} \\
\text { Beta }\end{array}$} & \multirow[t]{2}{*}{$\mathrm{t}$} & \multirow{2}{*}{$\mathrm{p}$} & \multirow[b]{2}{*}{$\mathrm{R}$} & \multirow[b]{2}{*}{ R Square } \\
\hline & $\mathrm{B}$ & St. Hata & & & & & \\
\hline $\begin{array}{c}\text { (Constant) } \\
\text { Memnuniyet }\end{array}$ & $\begin{array}{c}3,207 \\
, 299\end{array}$ & $\begin{array}{l}, 166 \\
, 044\end{array}$ & ,434 & $\begin{array}{c}19,271 \\
6,798\end{array}$ & $\begin{array}{l}, 000 \\
, 000\end{array}$ &, $434^{\mathrm{a}}$ &, 188 \\
\hline
\end{tabular}

a. Dependent Variable: Karar

Regresyon eşitliği "Karar $=\mathbf{3 , 2 0 7}+\mathbf{0 , 4 3 4}$ * Memnuniyet" şeklinde oluşturulmuştur. Anlamlılık (p) değeri 0,05 'ten küçüktür, bu bağlamda eşitliğin istatistiksel olarak anlamlı olduğu sonucuna ulaşılmaktadır. Seçmen memnuniyetinin seçmen kararı üzerinde \%18,8 oranında açıklayıcılığı bulunmaktadır ve bu sonuçlar H6 hipotezini desteklemektedir.

Tablo 7: Regresyon Analizi Sonuçları

\begin{tabular}{|c|c|c|c|c|c|c|c|}
\hline \multirow{2}{*}{ Model } & \multicolumn{2}{|c|}{$\begin{array}{c}\text { Unstandardized } \\
\text { Coefficients }\end{array}$} & $\begin{array}{c}\text { Standardized } \\
\text { Coefficients }\end{array}$ & $\mathrm{t}$ & $\mathrm{p}$ & $\mathrm{R}$ & $\mathrm{R}$ Square \\
\cline { 2 - 8 } & $\mathrm{B}$ & St. Hata & Beta & &, $339^{\mathrm{a}}$ &, 115 \\
(Constant) & 1,740 &, 369 & & 4,710 &, 000 & & \\
Seçime &, 431 &, 085 &, 339 & 5,080 &, 000 & & \\
Karş1 Tutum &, 439 & & & \\
\hline
\end{tabular}

a. Dependent Variable: Memnuniyet

Regresyon eşitliği "Memnuniyet $=\mathbf{1 , 7 4 0}+\mathbf{0 , 3 3 9}$ * Seçime Karşı Tutum" şeklinde oluşturulmuştur. Anlamlılık (p) değeri 0,05 ’ten küçüktür, bu bağlamda eşitliğin istatistiksel olarak anlamlı olduğu sonucuna ulaşılmaktadır. Seçime karşı tutumun seçmen memnuniyeti üzerinde \%11,5 oranında açıklayıcııı̆̆ bulunmaktadır ve bu sonuçlar H3 hipotezini desteklemektedir.

Tablo 8: Regresyon Analizi Sonuçları

\begin{tabular}{|c|c|c|c|c|c|c|c|}
\hline \multirow{2}{*}{ Model } & \multicolumn{2}{|c|}{$\begin{array}{c}\text { Unstandardized } \\
\text { Coefficients }\end{array}$} & $\begin{array}{c}\text { Standardized } \\
\text { Coefficients }\end{array}$ & $\mathrm{t}$ & $\mathrm{p}$ & $\mathrm{R}$ & $\mathrm{R}$ Square \\
\cline { 2 - 8 } & $\mathrm{B}$ & St. Hata & Beta & &, $374^{\mathrm{a}}$ &, 140 \\
(Constant) & 2,424 &, 217 & & 11,162 &, 000 & & \\
Reklama &, 450 &, 079 &, 374 & 5,686 &, 000 & & \\
Karş1 Tutum &, 400 & &
\end{tabular}

a. Dependent Variable: Memnuniyet

Regresyon eşitliği "Memnuniyet $=\mathbf{2 , 4 2 4}+\mathbf{0 , 3 7 4} *$ Reklama Karşı Tutum", şeklinde oluşturulmuştur. Anlamlılık (p) değeri 0,05 ’ten küçüktür, bu bağlamda eşitliğin istatistiksel olarak anlamlı olduğu sonucuna ulaşılmaktadır. Reklama karşı tutumun seçmen memnuniyeti üzerinde $\% 14$ oranında açıklayıcılığı bulunmaktadır ve bu sonuçlar $\mathrm{H} 2$ hipotezini desteklemektedir. 
Tablo 9: Regresyon Analizi Sonuçları

\begin{tabular}{|c|c|c|c|c|c|c|c|}
\hline \multirow{2}{*}{ Model } & \multicolumn{2}{|c|}{$\begin{array}{c}\text { Unstandardized } \\
\text { Coefficients }\end{array}$} & $\begin{array}{c}\text { Standardized } \\
\text { Coefficients }\end{array}$ & $\mathrm{t}$ & $\mathrm{p}$ & $\mathrm{R}$ & $\mathrm{R}$ Square \\
\cline { 2 - 8 } & $\mathrm{B}$ & St. Hata & Beta & &, $243^{\mathrm{a}}$ &, 059 \\
\hline (Constant) & 3,762 &, 157 & & 24,014 &, 000 & & \\
Reklama &, 202 &, 057 &, 243 & 3,538 &, 001 & & \\
Karş1 Tutum &, 2013 & & & \\
\hline
\end{tabular}

a. Dependent Variable: Karar

Regresyon eşitliği "Karar $=\mathbf{3 , 7 6 2}+\mathbf{0 , 2 4 3}$ * Reklama Karşı Tutum" şeklinde oluşturulmuştur. Anlamlılık (p) değeri 0,05 'ten küçüktür, bu bağlamda eşitliğin istatistiksel olarak anlamlı olduğu sonucuna ulaşılmaktadır. Reklama karşı tutumun seçmen kararı üzerinde \%5,9 oranında açıklayıcılığı bulunmaktadır ve bu sonuçlar H4 hipotezini desteklemektedir.

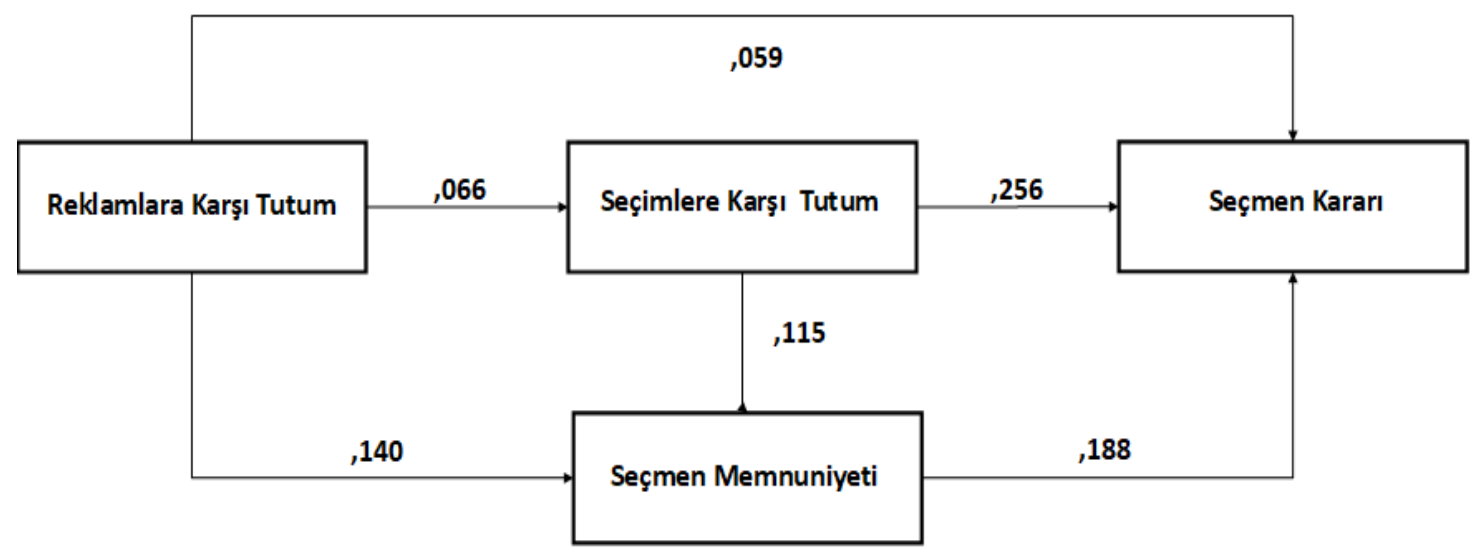

Şekil 1. Regresyon Analizi Sonuçları

Regresyon analizi sonuçları genel olarak değerlendirildiğinde bağımsız değişkenlerin bağımlı değişkenlerin üzerinde pozitif yönde etkisi olduğu sonucuna ulaşılmıştır (Şekil 1) ve kurulan hipotezlerin hepsi kabul edilmiştir.

\section{Sonuç}

$\mathrm{Bu}$ çalışmada reklamlara karşı tutum, seçimlere karşı tutum, seçmen memnuniyeti ve seçmen kararı arasındaki ilişkiler incelenmiştir. Çalışmada altı hipotez kurulmuş olup hipotezlerin hepsi kabul edilmiştir.

Çalışmada, seçimlerin katılımcılar için önemi analiz sonucunda belirlenmiştir (Mean: 4.257 - Std. Deviation: 0,250). Seçimlere karşı tutumun olumlu olmasında seçimin toplumu ilgilendiren bir olgu olması ve 4-5 y1lda bir (genel seçimler 4 yılda bir; yerel seçimler 5 yılda bir) olması da etkilidir. Seçimler bu bağlamda seçmenlerin memnuniyetini ve kararını da etkilemektedir. Literatürde özellikle USA başkanlık seçimleri üzerine araştırmalar yapılmakta olup seçmenlerin tutumlarını etkileyen değişkenlere odaklanılmaktadır. Dünyanın küreselleşmesi, dünya genelinde seçimlerde benzer uygulamalar ile benzer sonuçlara ulaşılmasına neden olmaktadır. Bu bağlamda, bu araştırmada da benzer sonuçlara ulaşılmıştır.

Seçmen kararının önemi çalışmada ortaya çıkmıştır (Mean: 4.275 - Std. Deviation: 0,208). Seçmenlerden oy vereceği parti ve adaylar belli olanlar veya olmayanlar seçim sonuçlarını belirlemektedir. Çünkü kararsız olanların seçim faaliyetlerine göre kararlarını vermesi hem oy kullanmaya çağn hem de parti ve adaylara destek için seçim kampanyalarında siyasal pazarlama reklamlarının kullanılmasının gerekliliği ortaya çıkarmaktadır. Literatürde seçmenlerin seçim öncesinde parti ve adaylar hakkında bilgiye ihtiyaç duymaları; seçim anında iç çatışma yaşamadan oy kullanmayı istemeleri; seçim sonrasında ise suçluluk duygusu hissetmemeyi istemeleri üzerinde 
durulmaktadır. Aynı sonuçlara bu araştırmada da ulaşılmaktadır. Seçmenlerin kararlarında benzer hassasiyetlere sahip oldukları görülmektedir.

Çalışmanın kısıtlarından ilki anketin 2019 yılı Şubat ve Mart aylarında İstanbul ili Bahçelievler ve Bakırköy ilçelerinde toplanmasıdır. Gelecek çalışmalar, İstanbul üzerine olursa farklı ilçeler de çalışmaya dahil edilerek daha fazla katılımcıya ulaşarak tekrar edilebilir. Farklı şehirler üzerinde de çalışma tekrarlanarak siyasal pazarlama reklamlarının seçmen kararındaki etkisi ölçülebilir.

Sonuç olarak, araştırmada seçmenlerin beğendiği veya desteklediği parti ve adayların seçmen memnuniyetini belirlediği anlaşılmıştır. Araştırmanın veri toplama aşamasında da katılımcıların memnuniyeti parti ve adayların kampanyalarına göre değişmekteydi. Araştırma şirketlerinin seçim zamanı açıkladığ 1 anket sonuçları da seçmenlerin memnuniyetini belirlemektedir. Ayrıca parti ve adayların önceki dönemdeki faaliyetleri ve bunlardan bahsetmeleri de memnuniyeti artırmaktadır.

\section{Kaynakça}

Bastos, M. T., Mercea, D. (2016). Serial activists: Political Twitter beyond influentials and the twittertariat. New Media \& Society, 18(10), 2359-2378. https://dx.doi.org/10.1177/1461444815584764

Burroughs, J. E., Rindfleisch, A. (2002). Materialism and well-being: A conflicting values perspective. Journal Consumer Research, 29(3), 348-370. https://doi.org/10.1086/344429

Durmuş, B., Yurtkoru, E. S., Çinko, M. (2011). Sosyal bilimlerde SPSS'le veri analizi, Beta Yayınc1lik

Ediraras, D.T., Tintri, D., Rahayu, D.A., Natalina, A., Widya, W. (2013). Political marketing strategy of Jakarta Governor Election in the 2012s. Procedia-Social and Behavioral Sciences, 81, 584-588. https://doi.org/10.1016/j.sbspro.2013.06.480

Gegez, E. (2010). Pazarlama araştırmalarl, Beta Yayıncıl1k

McNeill, D., Ottersen O.P. (2015). Global governance for health: how to motivate political change? Public Health, 129(7), 833-837. https://doi.org/10.1016/j.puhe.2015.05.001

Mejova, Y., Srinivasan, P. (2012). Political speech in social media streams: Youtube comments and Twitter posts. Proceedings of the 4th Annual ACM Web Science Conference, WebSci'12. 205-208. https://dx.doi.org/10.1145/2380718.2380744

Nakip, M. (2005). Pazarlama araştırmalarına giriş, Seçkin Yayıncılık

O'Cass, A. (2002). "Political advertising believability and information source value during elections," Journal of Advertising, 31(1), 63-74. https://doi.org/10.1080/00913367.2002.10673661

Pal J., Gonawela, A. (2017). Studying political communication on Twitter: The case for small data. Current Opinion in Behavioral Sciences, 18(1), 97-102. https://dx.doi.org/10.1016/j.cobeha.2017.09.009

Pinkleton, B. E., Nam-Hyun U., Austin E. W. (2002). An exploration of the effects of negative political advertising on political decision making, Journal of Advertising, 31(1), 13-25. https://doi.org/10.1080/00913367.2002.10673657

Powell, L., Cowart J. (2015). Political campaign communication: Inside and out. Routledge https://doi.org/10.4324/9781315265049 
Ross, K., Fountaine, S., Comrie, M. (2015). Facing up to Facebook: Politicians, publics and the social media(ted) turn in new zealand. Media, Culture \& Society, 37(2), 251-269. https://doi.org/10.1177/0163443714557983

Strömbäck, J. (2007). Political marketing and professionalized campaigning, Journal of Political Marketing, 6(2-3), 49-67. https://dx.doi.org/10.1300/J199v06n02_04

Yang, X., Chen, B. C., Maity, M., Ferrara, E. (2016). Social politics: Agenda setting and political communication on social media. In E., Spiro \& Y. Y. Ahn (Eds.), Social informatics. SocInfo 2016. Lecture Notes in Computer Science, (pp. 330-344). Springer. https://dx.doi.org/10.1007/978-3-319-47880-7_20

Trthaber. (2019, Ekim 8). Trump'ın vazgeçemediği basın sözcüsü: Twitter. https://www.trthaber.com/haber/dunya/trumpin-vazgecemedigi-basin-sozcusu-twitter434564.html 